Article

\title{
Polycomplexes of Hyaluronic Acid and Borates in a Solid State and Solution: Synthesis, Characterization and Perspectives of Application in Boron Neutron Capture Therapy
}

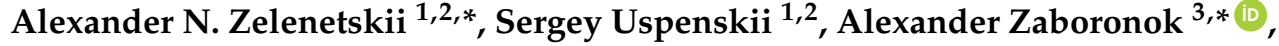 \\ Georgij Cherkaev ${ }^{1,2}$, Alexander Shchegolihin ${ }^{4}$, Bryan J. Mathis ${ }^{3}$, Mikhail Selyanin ${ }^{1}$, \\ Tetsuya Yamamoto ${ }^{5}$ and Akira Matsumura ${ }^{3}$ \\ 1 R\&D Center "Suisselle," CEI3, rue Galilée 6, 1400 Yverdon-les-Bains, Switzerland; \\ s.a.uspenskii@mail.ru (S.U.); georgij.cherkaev@gmail.com (G.C.); selyanine@martinex.ru (M.S.) \\ 2 Institute of Synthetic Polymer Materials, Russian Academy of Sciences, Profsoyuznaya st. 70, \\ 117393 Moscow, Russian \\ 3 Faculty of Medicine, University of Tsukuba, 1-1-1 Tennodai, Tsukuba 305-8575, Japan; \\ bmathis@md.tsukuba.ac.jp (B.J.M.); a-matsumur@md.tsukuba.ac.jp (A.M.) \\ 4 Institute for Biochemical Physics, Russian Academy of Sciences, Kosygina st. 4, 119334 Moscow, Russian; \\ chembio@sky.chph.ras.ru \\ 5 Department of Neurosurgery, Graduate School of Medicine, Yokohama City University, 3-9 Fukuura, \\ Kanazawa, Yokohama 236-0004, Japan; y_neuros@yokohama-cu.ac.jp \\ * Correspondence: anzel@ispm.ru (A.N.Z.); a.zaboronok@md.tsukuba.ac.jp (A.Z.); \\ Tel.: +7-495-330-0597 (A.N.Z.); +81-29-853-3220 (A.Z.); Fax: +7-495-718-3404 (A.N.Z.); +81-29-853-3214 (A.Z.)
}

Received: 5 January 2018; Accepted: 10 February 2018; Published: 13 February 2018

\begin{abstract}
In this report, we propose a new polyborate fragment synthesis strategy along the whole chain of the polysaccharide hyaluronic acid (HA) to produce boron neutron capture therapy (BNCT) compounds. Under high pressure and deformatory solid-state conditions, polymolecular system formation takes place due to association of phase-specific transition components into a more or less distinct microscopic organization. Fourier transform infrared (FTIR) spectroscopy shows that HA and polyborates form a network of cyclic polychelate complexes. HA acts as a multidentate ligand using carboxylic and hydroxyl proton donor groups to link oxygen atoms in $\mathrm{B}-\mathrm{O}-\mathrm{B}$ bonds and borate-anions $\mathrm{B}-\mathrm{O}(-)$ : $\mathrm{O}-\mathrm{H} \cdots \mathrm{O}, \mathrm{O}-\mathrm{H} \cdots(-) \mathrm{O}$. With free electron pairs in heteroatoms $-\mathrm{O}(:) \cdots \mathrm{B},-\mathrm{N}(:) \cdots \mathrm{B}, \mathrm{HA}$ can act simultaneously as an electron donor. Nuclear magnetic resonance (NMR) with ${ }^{13} \mathrm{C}$ and ${ }^{1} \mathrm{H}$ reveals a preserved complex interaction after both solubilizing and attenuating the HA-polyborate system. Stability of the product in water, low cost, ease of synthesis and scalability of manufacturing indicate that HA-polyborate complexes might have advantages over current chemotherapeutic approaches in creating therapeutic agents for BNCT.
\end{abstract}

Keywords: hyaluronic acid; borates; solid state synthesis; Fourier transform infrared spectroscopy; nuclear magnetic resonance; boron neutron capture therapy

\section{Introduction}

Recently, great progress has been achieved in the synthesis of boron-10-containing pharmaceutical compounds [1-10] for boron neutron capture therapy (BNCT). The synthesized compounds can deliver boron-10 to tumour tissues at a concentration of $40 \mu \mathrm{g} / \mathrm{g}$, which is 3.5 times higher than in normal tissues. These concentrations allow for therapeutic impact on tumours while low background spares normal tissue. However, typical synthesis methods using polyhedral boron face an obstacle in the area 
of biocompatibility. To provide biocompatibility it is necessary to create a system of covalently-bonded elements in one complex molecule but polyhedral architecture is biologically xenogeneic leading to the need for natural carriers that also happen to cause cell growth and proliferation. These carriers include oligonucleotides, free amino acids, peptides, lipids, phospholipids and carbohydrates. Additionally, as direct bonding is typically impossible, active reagents such as diisocyanates, biscarbodiimides etc. are used as intermediate bridges (spacers) that may also have xenogeneic effects on cells. A typical polyhedral boron-containing synthesis cascade consists of multiple transformations of the original bioorganic substance, each with a risk of creating some unintended effect. We suggest here that creation of a supramolecular bond system of polyborates and HA based on repeated chelate complexes along the molecular chain and $\mathrm{B}-\mathrm{O}-\mathrm{C}$ bonds of alpha-diols with the borate is an efficient alternative to the covalent bonding of boron fragments with cell membrane-binding saccharides at the end of the multicomponent molecular chain.

Thus, the aim of the study was to create a polycomplex system consisting of a polysaccharide (HA) with the most biochemically adaptive and aqueous-stable structure and a polyborax chain formed from partial tetraborate neutralization (Figure 1). The current study is also the initial step in using the proposed technology for the synthesis of complex boron and high-Z element compounds for in-sample dosimetry, tumour localization and boron dose evaluation during BNCT.

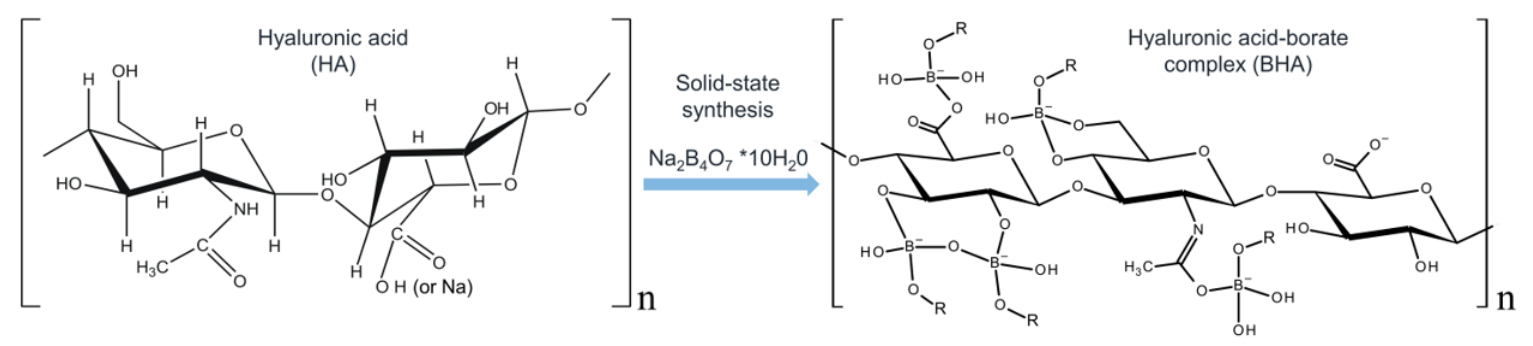

Figure 1. The scheme of synthesis and structure of the hyaluronic acid-borate complex. Several possible ways of coordination in the complex are presented. The interaction of the polysaccharide with $\mathrm{Na}_{2} \mathrm{~B}_{4} \mathrm{O}_{7}$ (Borax) can lead to the formation of coordination bonds of the boron atom with all suitable electron-donating atoms. As a result, a number of complexes are formed in an aqueous solution at thermodynamic equilibrium. The totality of these complexes can be considered as a supramolecular (dynamic) system-the polysaccharide/borate/polyborate.

\section{Materials and Methods}

BHA solid state synthesis was conducted as follows: sodium hyaluronate of bacterial origin with a molecular weight of $1 \times 10^{6} \mathrm{Da}$ (Shiseido Co., Ltd., Tokyo, Japan) and sodium tetraborate decahydrate $\left(\mathrm{Na}_{2} \mathrm{~B}_{4} \mathrm{O}_{7} \cdot 10 \mathrm{H}_{2} \mathrm{O}\right.$, Sigma-Aldrich, St. Louis, MO, USA) were mixed at mole ratios of 4:1 and 1:1 and ground in an agate mortar. For reactive mixing, the two components were processed in Bridgman anvils with the deformation at a pressure of $1 \mathrm{GPa}$ and a rotation angle of $500^{\circ}$, which is linearly related to the deformation (as described previously [11]) and at the twin-screw extruder, especially equipped for maximal forces in extrusion of solid mixtures.

In FTIR, the spectra of the tested compounds were recorded with infrared Fourier spectrometers VERTEX-70 (Bruker Optik GmbH, Ettlingen, Germany) and FTIR-1720 (PerkinElmer, Inc., Waltham, MA, USA). Depending on the physical condition of the analysed sample, appropriate spectrum recording modes such as transmission, incomplete internal reflection (IIR) and diffuse reflection-transmission (DRAFT) were selected.

NMR spectra were recorded with a Bruker Avance II 300 spectrometer (Bruker, Ettlingen, Germany) with a working frequency of $300.13 \mathrm{MHz}$ for ${ }^{1} \mathrm{H}, 75.47 \mathrm{MHz}$ for ${ }^{13} \mathrm{C}$ and $96.29 \mathrm{MHz}$ for ${ }^{11} \mathrm{~B}$ in deuterium oxide $\left(\mathrm{D}_{2} \mathrm{O}\right)$ solutions. The concentration of solutions was $10 \%$ by mass. Dimethylsulfoxide (DMSO) $(\delta=2.5 \mathrm{ppm})$ was used as an internal standard for ${ }^{1} \mathrm{H}$ and ${ }^{13} \mathrm{C}$ spectra and trifluoride etherate was an external standard for ${ }^{11} \mathrm{~B}(\delta=0 \mathrm{ppm})$. 
In the interpretation of the HA spectra we used our own data, ASTM standards and numerous literature data [12-15].

\section{Results}

\subsection{Fourier Transform Infrared Spectroscopy}

In comparative IR spectra of the Bridgman anvil deformation products, we can observe significant differences in the spectra of the products compared to the reagents. To analyse the changes and, if possible, to determine the character of reagent reactions, the spectra are divided into regions corresponding to known, characteristic (most clearly interpretable) absorption by HA and borate groups. These regions are $3650-2750,1750-1200 \mathrm{~cm}^{-1}$ (with two variants of normalization: by the $\mathrm{C}-\mathrm{H}$ absorption in the valence region and deformational oscillations of these groups and also by the maximum intensive band in this spectral region), $1200-880$ and $900-580 \mathrm{~cm}^{-1}$. Although the data are too complex to discover every facet of the reaction, primary changes in characteristic regions of the spectra in the post-reaction mixture gives a clear path to forming a hypothesis of the interaction. HA and polyborates can form a net of cyclical polychelate complexes, where HA plays the role of a polydentate ligand. It uses carboxyl and carbonyl groups as proton donors in bonds with O-atoms of $\mathrm{B}-\mathrm{O}-\mathrm{B}$ bonds and borate-anions $\mathrm{B}-\mathrm{O}(-)$ : $\mathrm{O}-\mathrm{H} \cdots \mathrm{O}, \mathrm{O}-\mathrm{H} \cdots(-) \mathrm{O}$ and at the same time acts as an electron-donor due to the free electron pairs in heteroatoms: $-\mathrm{O}(:) \cdots \mathrm{B},-\mathrm{N}(:) \cdots \mathrm{B}$. At the same time, the polysaccharide and polyborate form auto-associative arrangements which are typical for these compounds: intra- and intermolecular equatorial hydrogen bonds in HA in combination with dispersion interactions of cyclic pyranose rings in the axial direction. This preserves the spiral polysaccharide structure in slightly changed form and all coordinational bonds of polyborate and borate compounds with 3rd and 4th order- coordinating B atoms. This very mobile system of linkages and bonds are destroyed in accordance with the equilibrium constants of each individual complex in the given environment. Chelate formations stabilize the formation as they create a system of proton transfer to the rings to affect an anchimeric increase in the interaction.

\subsubsection{The Absorption Region of $\mathrm{OH}-$, $\mathrm{NH}-$ and $\mathrm{CH}-$ Valent Oscillations is $3650-2750 \mathrm{~cm}^{-1}$}

In the product spectra in Figure 2, redistribution by intensity and the maximum absorption bands is seen, characterizing valence vibrations of polyassociates of $\mathrm{X}-\mathrm{H}$ groups compared to initial substances. Here, the peak entirely disappears at $3494 \mathrm{~cm}^{-1}$ of borax (the absorption by $\mathrm{vOH}-$ groups of crystallization water) and the peak maximum becomes more intense and narrow, located at $3350 \mathrm{~cm}^{-1}$. A noticeably sharp absorption maximum of $\mathrm{OH}$ and $\mathrm{NH}$ amide groups can be seen, hyperchromically shifted compared to the spectrum of HA. Such a shift is possible due to the neutralization of some $\mathrm{COOH}$ - groups. At the same time, the hydrogen bond structure is characterized by a greater polydispersity of associates. If we accept that there is much less water in the product than in borax, then a part of the HA hydroxyl groups and acidic borates absorb in the region close to the $3000-2900 \mathrm{~cm}^{-1}$. The spectrum is clearly not additive making it evident that it is slightly expanded by increasing the amount of borax. It is therefore possible that hydrogen bonds are redistributed in polycomplexes when ratios of the reagents are changed. It can be stated that the system of hydrogen bonds in HA after deformation with borax has undergone significant changes. This is particularly obvious when comparing the absorption by bound $\mathrm{OH}$ - groups with absorption bands of $v-\mathrm{CH}$ in which the high ratio of borax/HA (green curve) in the product is overlapped by the shift of $v-\mathrm{OH}$ in the polyassociate. Thus, a particularly strong hydrogen bonding between the components of the system is shown and this fact points to the chelate structure of the binding. 


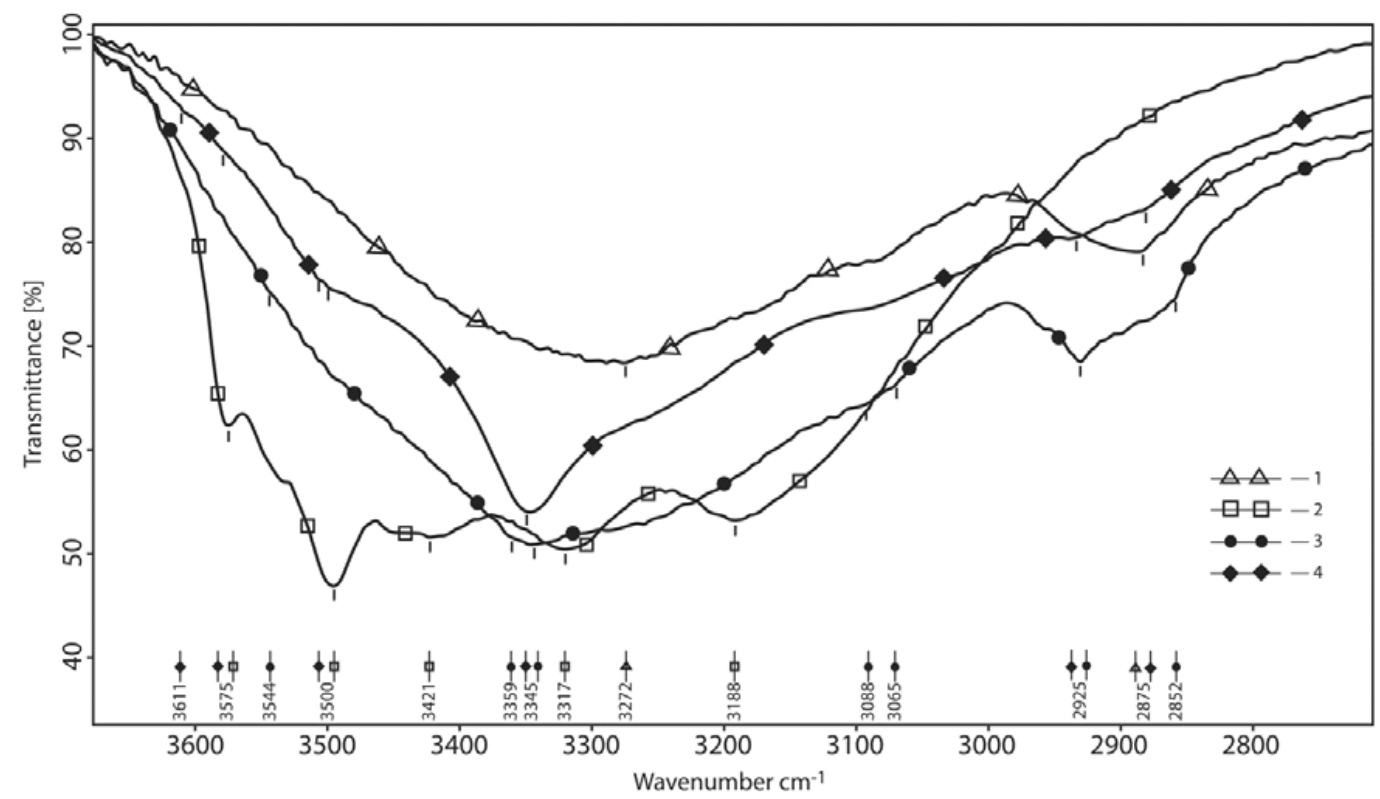

Figure 2. The area of $\mathrm{C}-\mathrm{H}, \mathrm{N}-\mathrm{H}$ valent $\mathrm{HA}$ oscillations and borate oscillations (normalized by $\mathrm{CH}$ ). 1-hyaluronic acid; 2-reaction product at the mole-link ratio of HA/g(gram)-atom B 1/4; 3-borax; 4 -reaction product at the mole-link ratio of $\mathrm{HA} / \mathrm{g}$ (gram)-atom B 1/1.

\subsubsection{The Area of $1750-1200 \mathrm{~cm}^{-1}$ of the Carbonyls and Amide Bonds}

The following changes, which are not relevant to the additive range, can be seen in this area when normalized by the maximum intensity (Figure 3), which allows accurate determination of the change in the position of the absorption bands. Two peaks at 1677 and $1638 \mathrm{~cm}^{-1}$ in the borax spectrum turn into a shoulder at $1666 \mathrm{~cm}^{-1}$ of the main Amide-I band with an absorption maximum of $1603-1609 \mathrm{~cm}^{-1}$. The lower frequency shoulder at $1557 \mathrm{~cm}^{-1}$ (Amide-II band, with the overlapping carboxylate peak $v_{\mathrm{a}}$ $\left.\left(\mathrm{CO}_{2}-\right)\right)$ slightly shifts into the low-frequency area $\left(10 \mathrm{~cm}^{-1}\right)$ allowing for accurate determination of the change in the position of the absorption bands.

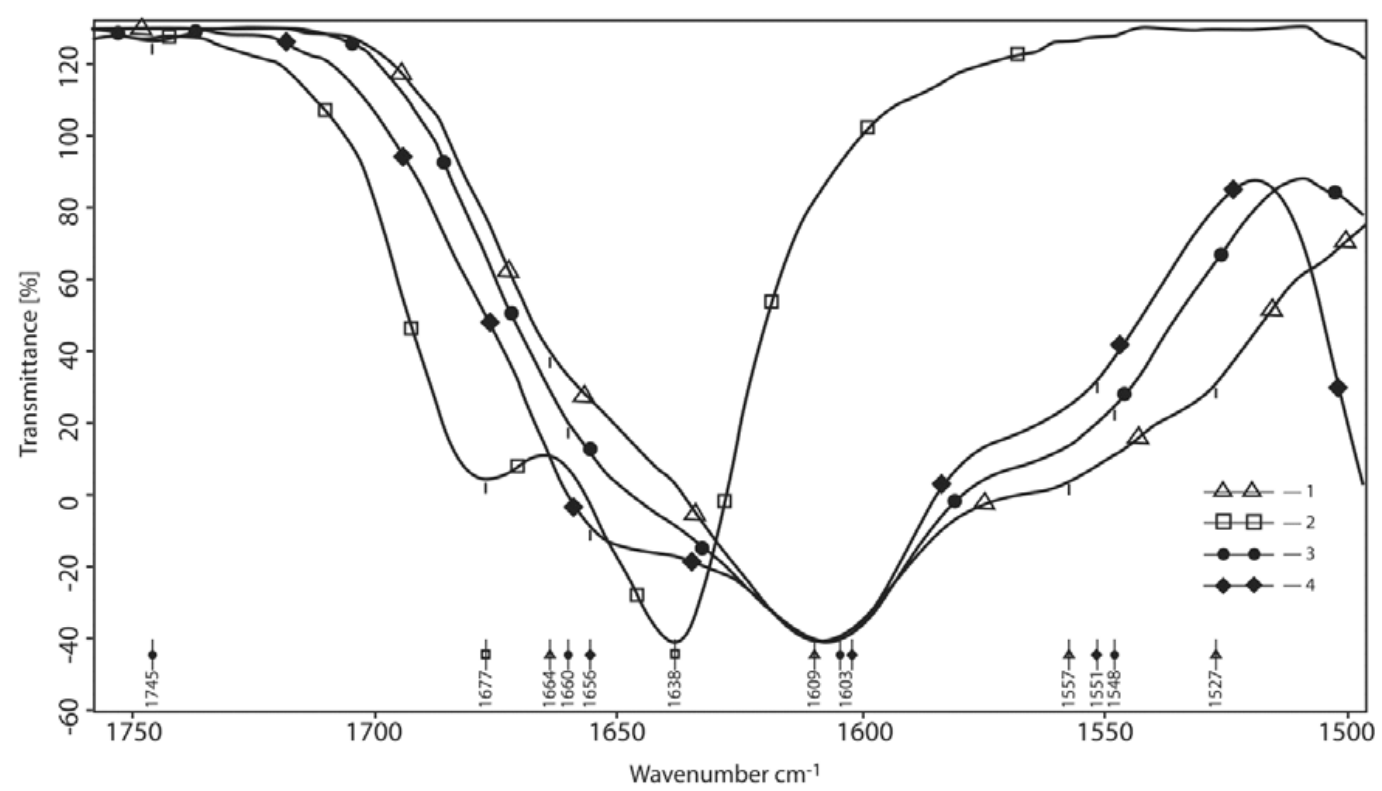

Figure 3. The area of carbonyls and amide bonds (normalized by the maximum intensity). 1-hyaluronic acid; 2-reaction product at the mole-link ratio of HA/g(gram)-atom B 1/4; 3-initial component-borax; 4-reaction product at the mole-link ratio of HA/g(gram)-atom B 1/1. 
An alternate method is to normalize signal with respect to the fixed - $\mathrm{CH}$ band in the HA spectrum. (Figure 4). Using this method reveals that the absorption intensity of the Amide-I band (maximum at 1603-1609 $\mathrm{cm}^{-1}$ ) sharply descends in comparison to the HA spectrum but the shoulders of the $1660 \mathrm{~cm}^{-1}$ bands greatly increase in intensity. Since these bands are also likely to be Amide-I bands, it is obvious that the condition of the HA amide and carboxyl groups in the reaction product is greatly changed. In fact, they are similar to the spectra of the salt form of the acid (HA). In the acid form, HA carbonyls absorb at lower frequencies than the salt due to the hydrogen bonding of $\mathrm{C}=\mathrm{O} \cdots \mathrm{HOOC}-$ which reduces the force constant of the bond. Such strong shifts of the carbonyl band are not new to amides and thus, in dimethylformamide, according to the degree of the association (tetramer, trimer, dimer and monomer), the Amide-I band is shifted by $90 \mathrm{~cm}^{-1}: 1650,1655,1659$ and $1741 \mathrm{~cm}^{-1}$ [15]. It is known that doublet of the bands 1663 and $1626 \mathrm{~cm}^{-1}$ in the spectrum of alpha-chitin (which is close in the structure to the HA polysaccharide with the same acetamido group) refers to $\vee \mathrm{C}=\mathrm{O}$ oscillations, corresponding to two types of $\mathrm{H}$ [hydrogen]-bonds in which the $\mathrm{C}=\mathrm{O}$ - group in the chitin takes part [16]. Consistent with this hypothesis is also the shift of the shoulder of the Amide-II HA band to the lower frequency region. These bands react to the destruction of associated bonds in the opposite manner of Amide-I. Similarly, dimerized formamide absorbs at $1552 \mathrm{~cm}^{-1}$ and the monomer at $1636 \mathrm{~cm}^{-1}$. The bands of the asymmetric stretching vibrations of $\mathrm{COO}(-)$ are in the same region, $1560 \mathrm{~cm}^{-1}$ but the lowered absorption frequency of the Amide-II band is evident. Peaks corresponding to the absorbance of sodium borate at 1677 and $1638 \mathrm{~cm}^{-1}$ disappeared in the product. Therefore, it is clear that this borate crystallization water was replaced by another ligand. The new absorption peak at $1481 \mathrm{~cm}^{-1}$ appears in the products, which is seen from the spectra that are normalized with respect to maximum intensity. This peak is absent from both initial materials and, therefore, must be the product of the reaction. In borate chemistry, such absorption is associated with changing of the number of $\mathrm{B}-\mathrm{O}-$ bonds in the borate grid with the addition of electron-acceptor and electron-donor reagents. That is to say, it is specifically the interaction of the borate with HA by carboxyl and carbonyl groups as proton donors with $\mathrm{O}$ atoms of $\mathrm{B}-\mathrm{O}-\mathrm{B}$ bonds and borate anions $\mathrm{B}-\mathrm{O}(-)$ : $\mathrm{O}-\mathrm{H} \cdots \mathrm{O}, \mathrm{OH} \cdots(-) \mathrm{O}$ as well as the ability of free electron pairs of hetero-atoms to be electron-donors in this manner: $-\mathrm{O}(:) \cdots \mathrm{In},-\mathrm{N}(:) \cdots \mathrm{B}$. It is significant that this peak is reduced and bathochromically shifted out $\left(1461 \mathrm{~cm}^{-1}\right.$ shoulder $)$ as HA content in the product increases. This specific spectral region, however, is the absorption region of the $\mathrm{B}-\mathrm{O}$ esoteric bonding of the boric acid, $\mathrm{R}-\mathrm{O}-\mathrm{B}$, which is consistent with the binding principle of pyranose $\alpha$-hydroxyl groups with boron (i.e., borate may be singly bonded or simultaneously bonded with two $\alpha$-diol groups) [17]. The $v(\mathrm{CO})+\delta(\mathrm{OH})$ bands, corresponding to the frequency overlapping of the valent vibrations of the $\mathrm{C}-\mathrm{O}$ and deformation vibrations of $\mathrm{OH}$ in the $\mathrm{HA}$ spectrum, lie at 1399 $\mathrm{cm}^{-1}$ and in products \#2 and \#4 at 1407 and $1426 \mathrm{~cm}^{-1}$. Thus, aliphatic hydroxyls are strongly bonded in the product and clear borate binding can be seen. This absorption is attributed to the vibrations of $\mathrm{C}-\mathrm{O}-\mathrm{B}$ bonds in the boric acid esters. A typical borate peak appears in product $\# 2$ at $1333 \mathrm{~cm}^{-1}$ (borax is at $1362 \mathrm{~cm}^{-1}$ ) and this is the absorption by the $\mathrm{B}-\mathrm{O}(-)$ bond, linked to the long chain of the borate bonds. In addition, according to the literature [18], the peaks at $1340 \mathrm{~cm}^{-1}$ correspond to asymmetrical valence oscillations $\left(v_{\mathrm{a}} \mathrm{B}-\mathrm{O}\right)$ of various borate cycles (see Figure 2$)$. It can therefore be seen that in the product all the absorption bands vary greatly due to both the interaction with the polysaccharide and acid neutralization by the borax because, when neutralized in stages, borax forms polyborates. In equimolar acid amounts (sample \#4), the borax band shows insignificant shifts. This may be due to the lower share of the bonds in $\mathrm{C}-\mathrm{O}-\mathrm{B}$, the absorption of which overlaps the polyborate absorption bands. The two peaks which appear at 1260 and $1280 \mathrm{~cm}^{-1}$ in the spectrum of product $\# 1$ are bands of the $v(\mathrm{CO})+\delta(\mathrm{OH})$ type but the bonds in the product are of a very different character than in HA (shoulder at $1280 \mathrm{~cm}^{-1}$ ). Borax does not exhibit such absorption and neither do boric anhydrides or boric acid. However, such an absorption is characteristic for tri-, tetra- and pentaborate groups that may form during partial neutralization of borax by HA in the solid state. 


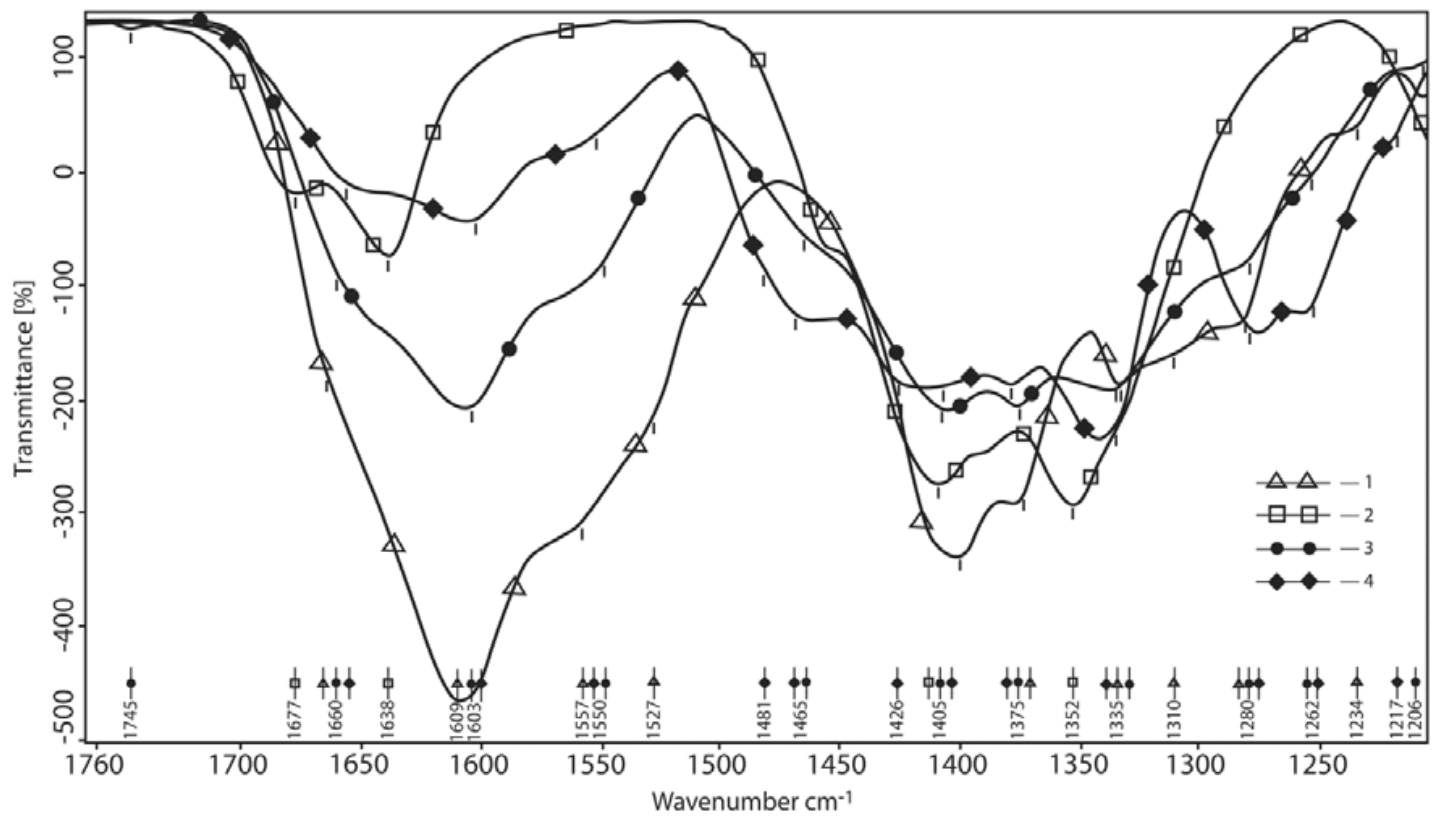

Figure 4. The area of carbonyls and amide bonds (the spectra are normalized by $\mathrm{CH}$ ). 1-hyaluronic acid; 2-reaction product at the mole-link ratio of HA/g(gram)-atom B 1/4 (actually the spectrum of HA); 3-borax; 4-reaction product at the mole-link ratio of HA/g(gram)-atom B 1/1.

\subsubsection{Oscillations Area of $\mathrm{C}-\mathrm{O}-$ Containing Bonds}

This area contains the valence oscillations of all acetal bonds (the ring and inter-ring bridges) as well as $\mathrm{C}-\mathrm{O}(\mathrm{H})$-bonds of carbinols. In this region, $\mathrm{C}-\mathrm{O}(\mathrm{B})$ bond (alkyl boric esters bond) absorption can also be assumed with high probability. The region of $1200-800 \mathrm{~cm}^{-1}$ is also an area of borate $\left(\mathrm{BO}_{4}\right.$ and borate rings) valence oscillations (Figure 5).

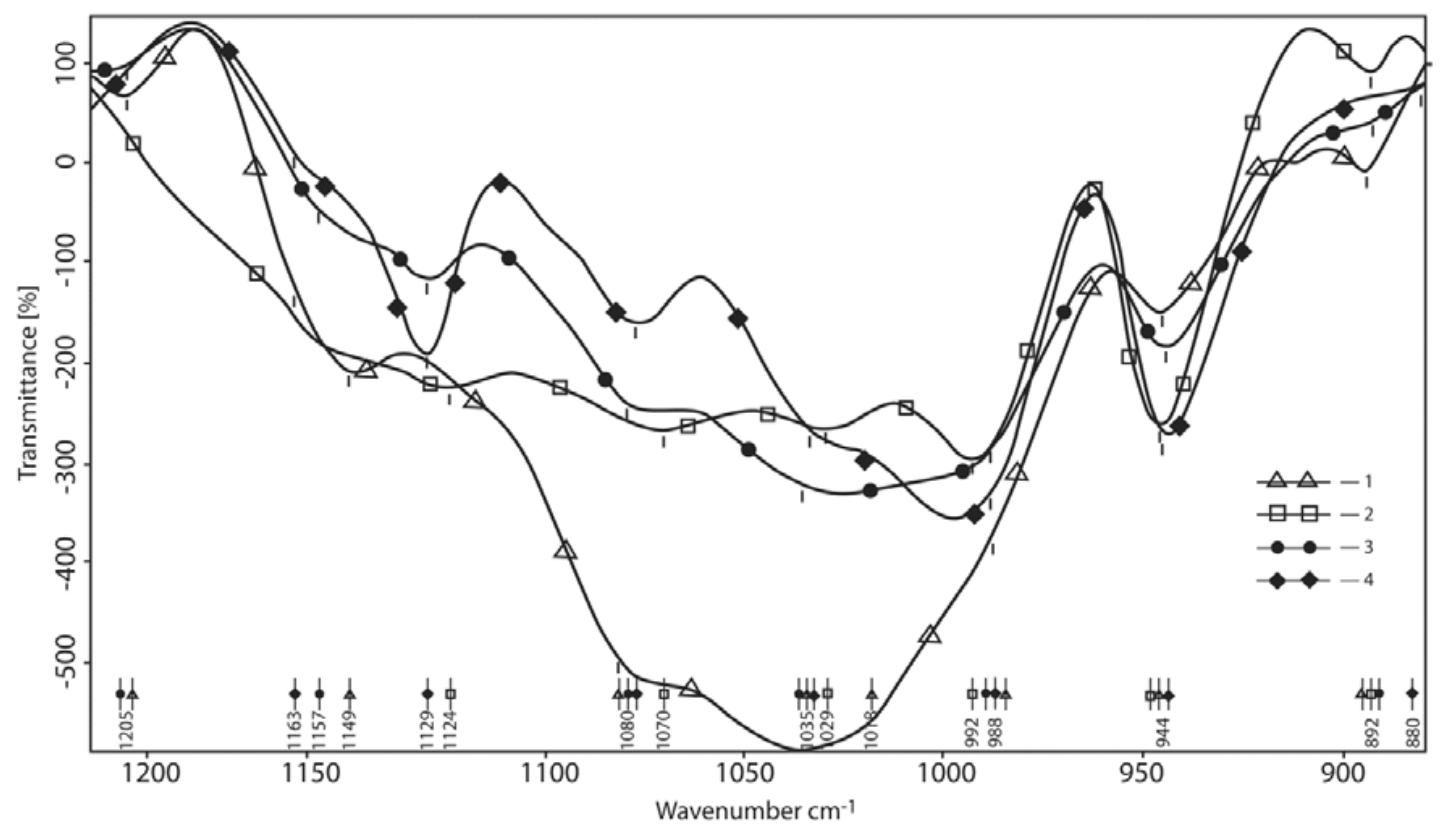

Figure 5. Oscillation area of the $\mathrm{C}-\mathrm{O}-$ containing bonds (normalized similarly by $\mathrm{CH}$ ). 1-hyaluronic acid; 2-reaction product at the mole-link ratio of $\mathrm{HA} / \mathrm{g}$ (gram)-atom B 1/4 (it is actually the spectrum of HA); 3-initial component-borax; 4-reaction product at the mole-link ratio of $\mathrm{HA} / \mathrm{g}$ (gram)-atom B $1 / 1$. 
The spectrum is normalized to $\mathrm{CH}$ so the redistribution of the absorption band intensity is clearly visible in the products compared to the HA spectrum. Normalization by $\mathrm{CH}$ should align the intensity of the spectral bands of the HA products with their ratios in the initial acid. However, in this case, we see significant changes in the spectra of products \#2 and \#4 not only in the intensities but also in band positions. The changes are generally qualitative and the HA spectrum is visible, albeit significantly changed. The main and the most intense signal in this region, namely the complex of the pyranose ring group bands (including their carbinol groups with the maximum at $1035 \mathrm{~cm}^{-1}$ and the shoulder at $1082 \mathrm{~cm}^{-1}$ ) is converted into a similar group of bands with the maximum at $995 \mathrm{~cm}^{-1}$ and the shoulder at $1033 \mathrm{~cm}^{-1}$. Products with more HA show more similarity in bands with the HA spectrum as expected. This is not only the shift of the HA group oscillations but a complex composition of reaction band product absorption bands and the HA spectrum with the peaks redistributed. Thus, in product \#2's HA spectrum, the shoulder at $1082 \mathrm{~cm}^{-1}$ corresponds with a peak maximum at $1077 \mathrm{~cm}^{-1}$ and instead of the maximum peak at $1149 \mathrm{~cm}^{-1}$ the peak shifts to $1129 \mathrm{~cm}^{-1}$. It should be taken into account that this is an area of pendulum oscillations of the average intensity of the ammonium ion $\left(\mathrm{NH}^{3+}\right)$.

Ammonium may be present in partially deacetylated HA and may form a complex with boron in the final product of the type $\mathrm{H}_{2} \mathrm{~N}(+)-\mathrm{B}(-)$. Borax gives the absorption maxima for borates, which in these spectral regions closely coincide with the absorption maxima of the products but the ratio of these peak intensities is quite different. Finally, the common peak for all reagents is at $944-945 \mathrm{~cm}^{-1}$. It is intense in the spectrum of borax and less intense in the HA spectrum, reflecting their differing natures. In borates (boron esters), these are the oscillations of cyclic diborate rings while in HA they are the $v(C C)$ oscillations of the pyranose ring. These groups cannot interact and their absorption is added together. Thus, we observe a strong interaction of all acetal and hydroxyl (alcohol) groups of the polysaccharide with the $\mathrm{O}$ atoms of $\mathrm{B}-\mathrm{O}-\mathrm{B}$ bonds and borate anions $\mathrm{B}-\mathrm{O}(-)$ at the same time by means of free electron pairs and hydrogen atoms $-\mathrm{O}(:) \cdots \mathrm{B}, \mathrm{O}-\mathrm{H} \cdots \mathrm{O}, \mathrm{O}-\mathrm{H} \cdots(-) \mathrm{O}$. In the cyclic framework, this translates to the formation of chelating complexes with an almost quantitative yield ratio of 1:1. Product \#4's spectra, where the HA amount is much higher, has a strong imposition of polysaccharide bands but the interaction is plainly visible. Furthermore, this absorption region of the $\mathrm{C}-\mathrm{O}-\mathrm{B}$ bonds is by means of the reaction: $\mathrm{B}-\mathrm{O}-\mathrm{B}+\mathrm{HO}-\mathrm{C}-\rightarrow \mathrm{B}-\mathrm{OH}+\mathrm{B}-\mathrm{O}-\mathrm{C}$. We clearly see this equilibrium in the NMR spectra of the products in aqueous solutions.

\subsubsection{Area of the Deformational and Packaging Oscillations (Overall Normalization by $\mathrm{CH}$ )}

Changes in deformational and packaging oscillations are also significant (Figure 6). It should be noted that the normal modes of oscillations are so mixed and delocalized that it is impossible to describe the complex wave motion with a simple single term. Therefore, description will be limited to a statement of changes in the spectra of initial compounds that primarily indicate the transformation of their molecular packing and the formation of a new system of intermolecular bonds. The peaks at $882 \mathrm{~cm}^{-1}$ in the spectra of borax and HA disappeared in the spectra of the products. This indicates the disappearance of out-of-plane, deformational oscillations of the $\mathrm{O}-\mathrm{H}(\mathrm{COOH})$ at $900 \mathrm{~cm}^{-1}$ after the reaction due to neutralization of these groups and their conversion to carboxylated forms. The product displayed a single peak at $820-825 \mathrm{~cm}^{-1}$. In the borax region of this spectrum, there are two absorption maxima at 808 and $831 \mathrm{~cm}^{-1}$. HA has a peak at $791 \mathrm{~cm}^{-1}$, which disappears in the products. Also, there are no peaks of borax in the spectra of products at 678 and $620 \mathrm{~cm}^{-1}$ but the peak of HA remains at $615 \mathrm{~cm}^{-1}$ from the variable oscillation of $\mathrm{NH}^{+}$. 


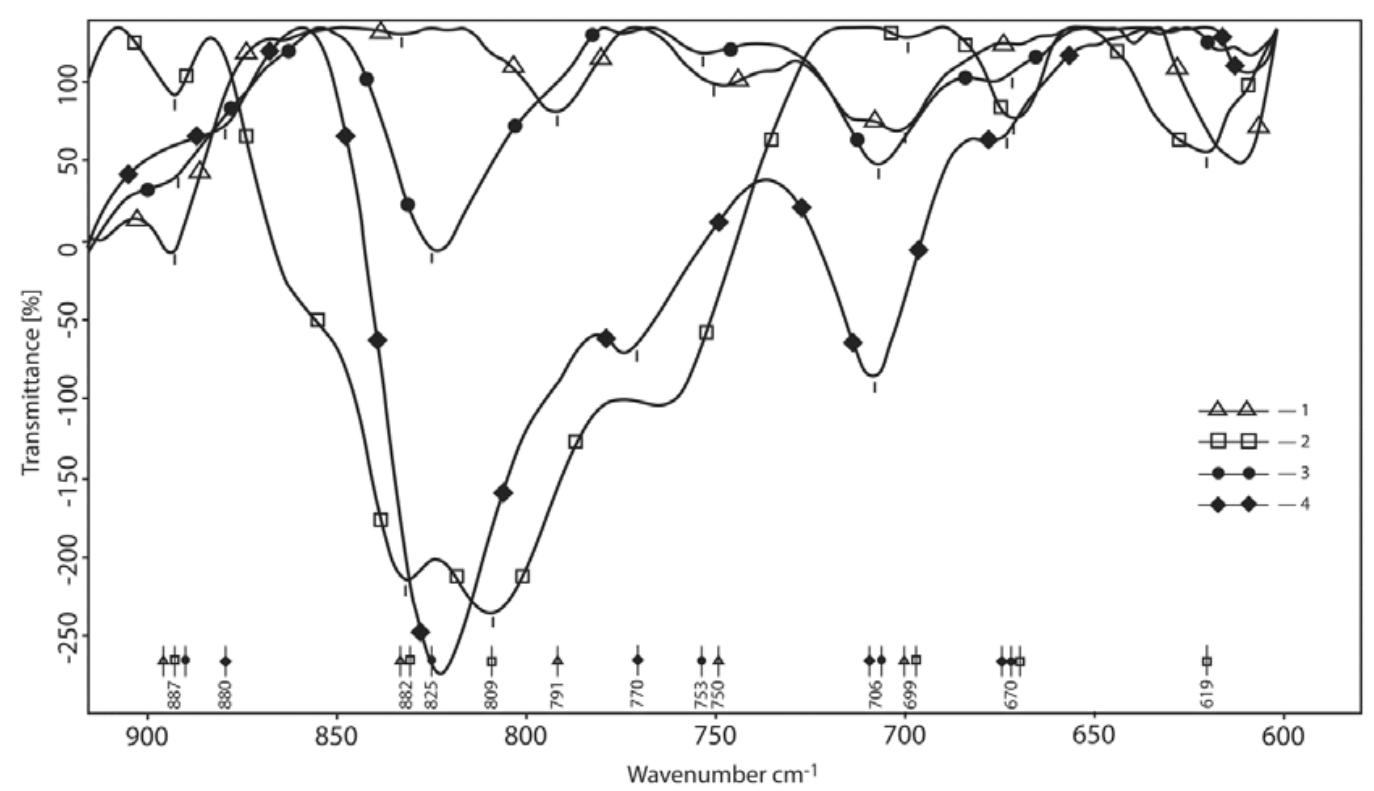

Figure 6. Area of the deformational and packaging oscillations (overall normalization by $\mathrm{CH}$ ). 1-hyaluronic acid; 2-reaction product at the mole-link ratio of HA/gram-atom B 1/4; 3-initial component-borax; 4 -reaction product at the mole-link ratio of HA/gram-atom B 1/1.

\section{2. ${ }^{1} \mathrm{H}$ and ${ }^{13} \mathrm{C}$ NMR Spectra of the Polycomplexes}

The complex interaction is preserved even in solubilisation and a potent dilution of the HA-polyborate system. In the proton spectrum of an aqueous hyaluronic acid solution (1:1, mole/mole) with borax and potassium hydroxide in a molar ratio of 1:4:4, respectively, general broadening of the signals is observed (Figure 7).

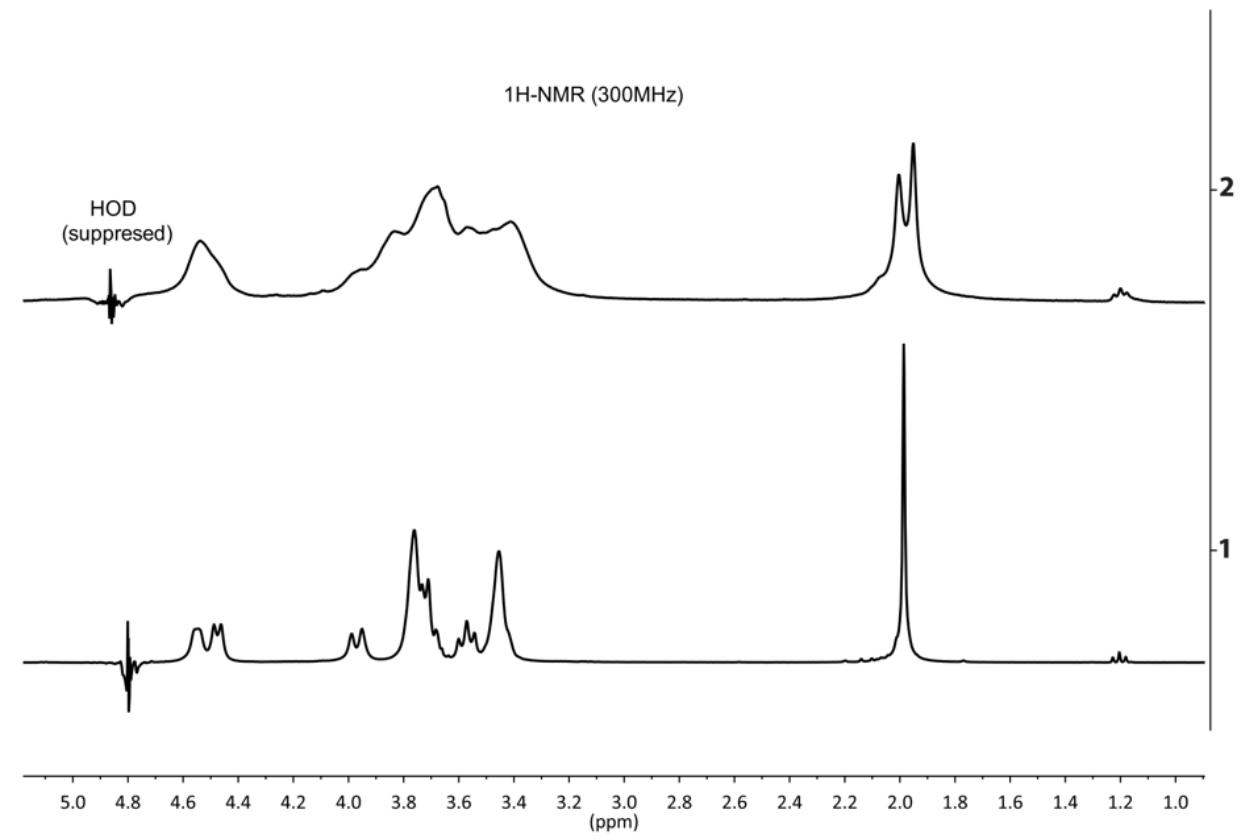

Figure 7. ${ }^{1} \mathrm{H}$ NMR spectra of the alkaline hyaluronic acid (1) and the hyaluronic acid, borax and potassium hydroxide solution in a molar ratio of 1:4:4, respectively (2). $\mathrm{pH}=14$ in all solutions. The borate formation is indicated by the general broadening of the spectrum and the splitting of the signal of the protons of the acetyl group (about $2 \mathrm{ppm}$ ). The triplet with the chemical shift of $1.17 \mathrm{ppm}$ belongs to the methyl group of the ethanol internal standard. 
An indication of borate derivative formation is the presence of two singlet signals from the protons of the acetyl groups which differ in the chemical shift by the value of $0.05 \mathrm{ppm}(15.6 \mathrm{~Hz})$. Relative integrated intensities of these signals are dependent on the ratio of HA:borax (Figure 8). We can also estimate the formation of the borate derivatives in the above-mentioned mixtures by splitting the signals of carbon atoms $\mathrm{C} 2$ and $\mathrm{C} 6$ of the $\mathrm{N}$-acetylglucosamine moiety in the ${ }^{13} \mathrm{C}$ spectrum (Figure 9).

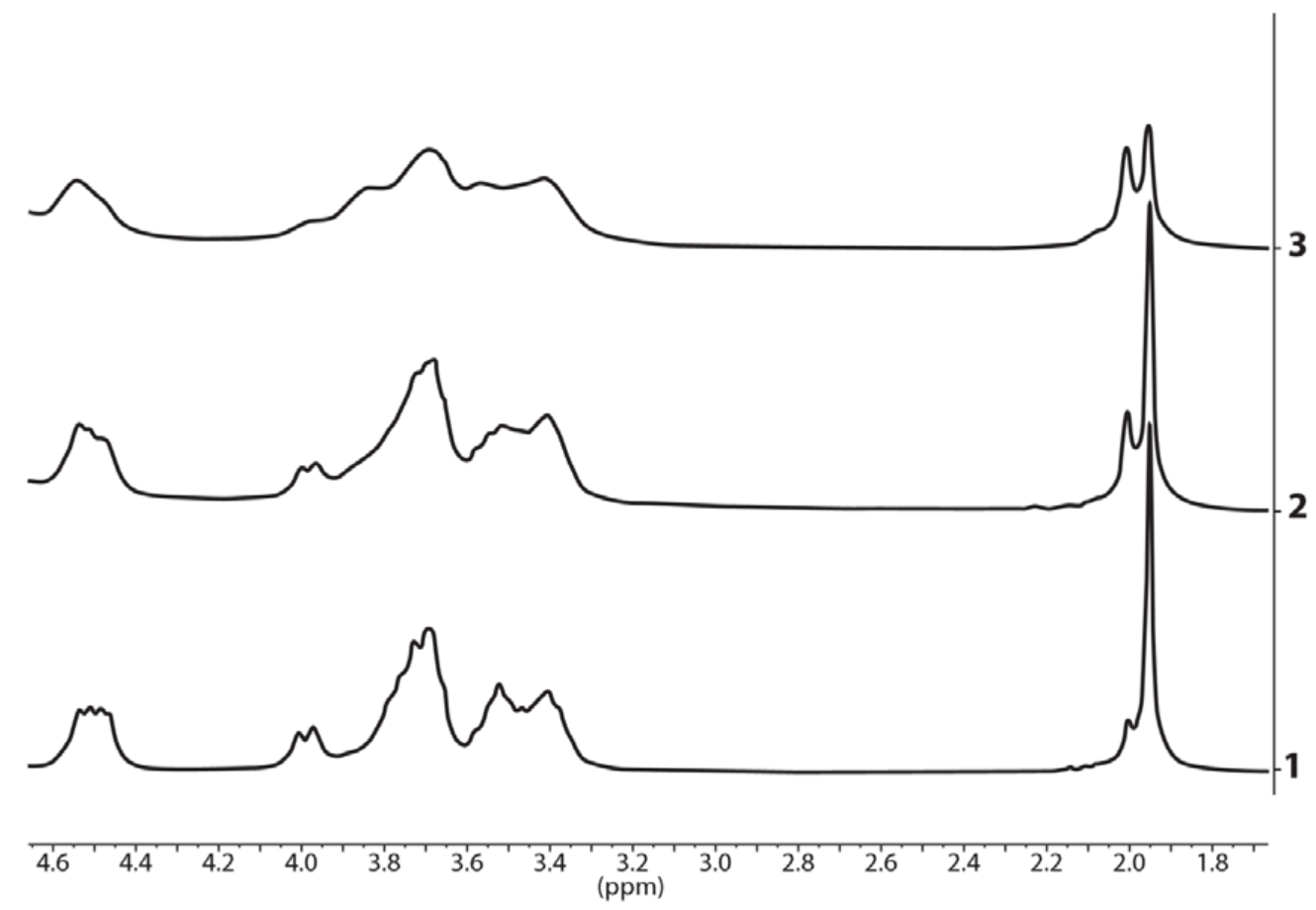

Figure 8. ${ }^{1} \mathrm{H}$ NMR spectra of the hyaluronic acid in the alkaline solution (1), the mixture of hyaluronic acid and borax in a molar ratio of 1:1 (2) and the mixture of hyaluronic acid, borax and potassium hydroxide in a molar ratio of 1:4:4 (3), respectively. $\mathrm{pH}=14$ in all solutions.

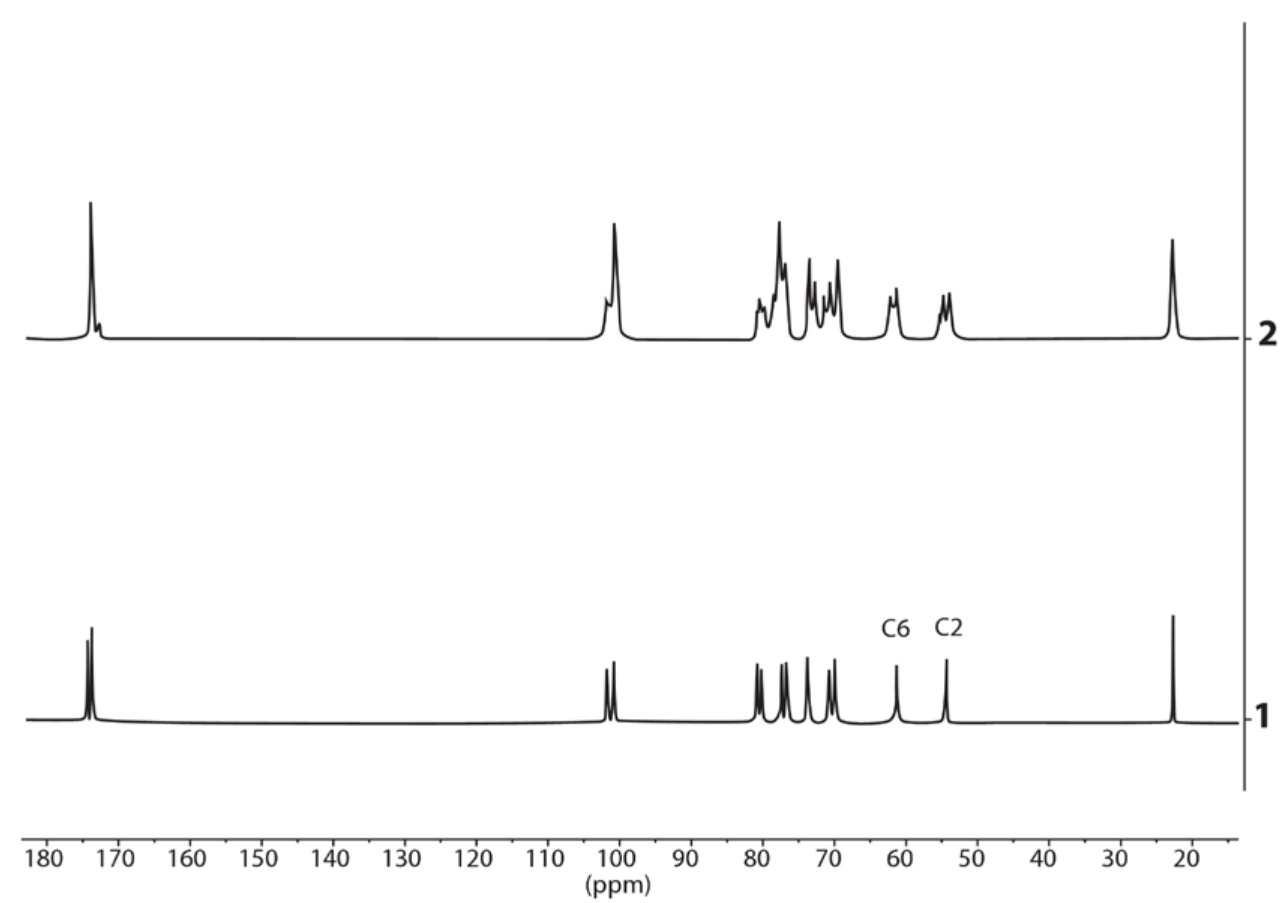

Figure 9. The spectra of ${ }^{13} \mathrm{C}$ hyaluronic acid in alkaline solution (1) and the mixture of hyaluronic acid, borax and potassium hydroxide in a molar ratio of 1:4:4, respectively (2). $\mathrm{pH}=14$ in all solutions. The borate formation is indicated by the splitting of the signal of carbon atoms C2 (about 55 ppm) and C6 (about $62 \mathrm{ppm}$ ) of the $\mathrm{N}$-acetylglucosamine moiety. 
According to rheological studies of diluted and semi diluted solutions of such complexes [19], sodium hyaluronate chains in the presence of borax are not prone to strong crosslinking. With the addition of borax, the viscosity sensitivity to temperature decreases-the effective activation energy is reduced from 20.4 to $16 \mathrm{~kJ} / \mathrm{mol}$. Such behaviour indicates an increase in chain flexibility in the sodium hyaluronate in the presence of borax, forming polyborates. This is a result of the screening of electrostatic interactions and the impact of borax on sodium hyaluronate macromolecular conformation (and therefore on the viscosity of its solutions). The formation of complexes with borates may lead to high magnitude increases in the rigidity of the sodium hyaluronate chains and even affect cross-linking in solutions with high borate concentrations.

\section{Discussion}

Various biologically active molecules that are selectively accumulated by tumour cells can be used as transporters in the synthesis of BNCT compounds with the knowledge that modification of biomolecules by inclusion of a boron fragment can significantly influence their biological properties. This may lead to a false mode of thinking whereby as much boron as possible is crammed into the polyhedron. However, the larger the polyhedron, the more diverse the transport component might be in its chemical structure or size and therefore the boron-containing fraction might be diluted by high molecular weight carriers. Furthermore, the toxicity of such compounds needed to carry high-boron polyhedrons might influence the effective therapeutic dosage for injection. With this in mind, a change to a verified, non-toxic carrier allows for increasing boron concentration by an order of magnitude, thereby solving any problems with over dilution as one gram-mole of the compound would deliver $6 \times 10^{23}$ molecules. It is plain to see that, for this reason, therapeutic plans must find the optimum intersection of the boron concentration and carrier size/toxicity curves.

Among the second-generation compounds used in BNCT one consists of polyhedral borane (BSH, [20]); another contains one boron atom in organoboric acid (BPA, [21-23]) and the efficacy of these compounds is far from perfect [24]. Another problem is the boron-10 isotope yield in the final product which depends on the boron-10-enriched original compound. Regardless of method, the synthetic production of polycyclic boron hydrides suffers from low yield of the polyhedron. Moreover, at each stage of the compound synthesis, the boron-10 isotope yield decreases and does not exceed a few percent.

In our study, selected ratios of boron gram-atom to HA mole-link were 4:1 and 1:1, respectively. The selection of ratios is dictated by the following reason: if the cyclic form of pyranose is combined with boron in a 2:1 molar ratio, 2 cyclic rings will form from the inter-ring linkage. At a 1:1 ratio, 1 cyclic ring is formed. Since HA mole-linkage consists of 2 cyclic rings, heteroborate links will form along the HA chain without deformation of the spatial grid that can cause severe changes in system viscosity. However, to precisely form this product, the task we have defined necessitates the selection of optimal boron concentrations in the mixture. From a BNCT manufacturing standpoint, it is better to saturate the product with as much boron as it can hold but for optimal boron accumulation in a tumour, strict stoichiometry of the complexes should be defined to ensure a maximal level of supramolecular binding.

It is known that claw-type complexes have a high binding energy and are very stable [25]. In conditions of high pressure and shear forces, polymolecular systems are formed by association with their transition to a specific phase having a more or less clearly defined microscopic organization. According to the definition given by Len, "Supramolecular chemistry-is a 'chemistry beyond the molecule' that studies the structure and functions of associations of two or more chemical species held together by intermolecular forces" [25].

Chelate complexes are most stable as they establish a system of cyclic transfers of protons and electron pairs that enhance the reaction in an anchimeric fashion. Binding of sugars with borate into an ion complex is a well-known reaction widely applied in the analytical chemistry of both boron and sugars [17,26-28]. As with all supramolecular systems, the polycomplex is expected to be stable in water solutions and its tumour selectivity can be increased by HA. As HA possesses multiplex 
interactivity with biological tissues, it is ideal as a carrier for targeting delivery of active compounds fused to it by synthetic processes [29]. It can interact with the fibroblast cell surface, as it selectively bonds to CD44 and RHAMM- specific receptors on the surface of the cytoplasmic membrane [30]. Due to its natural origin, HA shows such advantageous features as biocompatibility, biodegradability and nonimmunogenity. HA acts as a cellular signalling molecule during inflammation, wound healing, or cancer metastasis [31-33]. HA, together with its receptor (CD44) and degradation enzymes (HYAL-1, etc.), acts as a carcinolytic agent, suppressing tumour growth and metastasis and this is evidenced by accumulation of HA and its associated degradation enzymes within malignant tumours [29]. HA shows very fast elimination from all tissues and a long history of use in cosmetology proves its harmlessness even in very large doses [34,35]. Despite a number of studies devoted to mono- and disaccharides $[17,28]$ as of this report we are not aware of publications about complexing polyborates with HA.

Although most drugs are manufactured in liquid form, the more efficient method in the case of HA is reactionary allegation in a solid state (RASS) at high pressure and shear stress. A liquid phase method is inefficient because HA solutions are viscous and their reagent concentration is not high meaning that solution preparation requires prohibitively large amounts of water. On the other hand, polymer deformation at a high pressure maintains higher reagent concentrations. Additionally, deformation processing leads to the formation of charged conditions in the substance mass, disordering of its structure and polarization of molecules and these processes are intensified in the mutual deformation of biocomponent polymer mixtures. In spite of the rapid acceleration of the relaxation processes after pressure release, deformation-induced structural changes are often preserved, maintaining metastable structures even under elevated intrinsic energy conditions. Polymer mixtures (with or without low molecular weight reagents) have an additional advantage in that they can be exposed to elevated pressure and shear deformation to remove diffusion limitations that exist in reactions in solid state or highly viscous media. When subjected to high pressure and shear deformation (even in an extruder), unique but reliable behaviour is observed in mixtures of highly organized compounds with high cohesive energies such as cellulose, chitin and chitosan [36]. It is therefore relatively easy to produce chitosan salts with a variety of solid organic acids in high quantitative yield using a RASS-based extrusion method [37,38]. Until the present work, the solid-phase interaction of polysaccharides and, in particular, hyaluronic acid has not been studied.

Several issues should be addressed before further preclinical evaluation of the developed compound. Regarding the components of the synthesis, borax naturally causes alkalinisation of the solution. In NMR analysis, all tested solutions were made strongly alkaline, which reduces signal broadening in NMR spectra caused by both the high viscosity of HA, which decreases with an increase in the $\mathrm{pH}$ of the solution [39] and the inverse change in the $\mathrm{sp}^{2} / \mathrm{sp}^{3}$ states of the boron atom, where at a high concentration of alkali almost all boron atoms become tetracoordinate boron atoms (turn into the $\mathrm{sp}^{3}$ state). For the initial phase of biological experiments, we will need to adjust the $\mathrm{pH}$ to physiological ranges before performing the cytotoxicity tests.

The toxicity of any new anticancer compound is an important issue to be addressed before preclinical evaluation and prospective clinical use. Despite the abovementioned stability of claw-type complexes in general and the stability of synthesized compound in the tested solutions, changes in environmental conditions in biological systems can affect the complex and might lead to liberation of the borate species. Moreover, during BNCT itself, boron is destined to decay after the neutron irradiation. In such a case, if a boron complex is present in tumour cells, the toxicity of the decay products will cause an additional therapeutic effect, though presence in healthy tissues will cause unwanted side effects of the drug. Regarding this issue, the main task before biological testing will be the verification of the stability of the preparation in biological media and cell cultures.

In oncology, adjuvant therapy methods often balance on the verge of heal and harm for the organism as a whole, trading known risk for a guaranteed therapeutic effect. As our components are 
at the initial stage of development, we believe that the important issue of toxicity and the expected balancing of risk and therapeutic effect will be taken into account at all stages of further experiments.

\section{Conclusions}

BNCT is a promising method over standard radiation therapy from a standpoint of efficacy and safety while being unique in its influence on invasive tumours. However, enhancing the target effect of the neutron beam has been a key focus of translational research. Here, we report that BHA is a highly water stable and easy-to-manufacture compound. A description of the synthesis was provided, purity and concentration were determined empirically through FTIR and NMR and the full analysis of the HA-polyborate complex was elaborated. At this stage of the chemical analysis we can indicate that, compared to currently utilized BNCT agents, the proposed HA-polyborate complexes are characterized by the low cost of reagents, ease of synthesis, scalability of manufacturing and stability in water.

Of much interest in biomaterial engineering is the modification of existing compounds with additional functional groups to increase efficacy, solubility, delivery and specificity [39]. Peptides, organic groups and other inorganic elements might eventually be blended in specific ratios to give custom targeted therapy. To this end, hyaluronic acid is an excellent scaffold to attach these functional modifications to and we have shown that our HA-polyborate modification holds promise to benefit cancer therapy. Now that a cheap and easily synthesized HA compound is available, future research will be intensely focused on modification and empirical determination of the best functional groups to add to HA-polyborate complexes for customized results.

Acknowledgments: This work was partly supported by Grants-in-Aid for Scientific Research (B) [17K15797] and (B) $[26293320 \mathrm{H}]$ from the Japanese Ministry of Education, Culture, Sports, Science and Technology.

Author Contributions: Alexander Zelenetskii, Sergey Uspenskii, Alexander Zaboronok, Mikhail Selyanin and Tetsuya Yamamoto conceived and designed the experiments; Alexander Zelenetskii, Sergey Uspenskii, Alexander Zaboronok, Georgij Cherkaev and Alexander Shchegolihin performed the experiments; Alexander Zelenetskii, Sergey Uspenskii, Alexander Zaboronok and Bryan J. Mathis drafted the manuscript; Sergey Uspenskii, Alexander Zaboronok, Georgij Cherkaev and Alexander Shchegolihin analyzed the data; Alexander Zelenetskii, Sergey Uspenskii, Alexander Zaboronok, Bryan J. Mathis, Tetsuya Yamamoto and Akira Matsumura reviewed and edited the manuscript.

Conflicts of Interest: Mikhail Selyanin, M.D., is a chief co-founder of the R\&D Center "Suisselle," Yverdon-les-Bains, Switzerland and a president of the Group of Companies "Martinex," Moscow, Russian Federation, a company group devoted to development and commercialization of compounds for medical use. Alexander Zelenetskii, Sergey Uspenskii, Georgij Cherkaev are part-time employees of the R\&D Center "Suisselle," Yverdon-les-Bains, Switzerland. Alexander Zelenetskii and Mikhail Selyanin are co-holders of Patent 2445978, Russian Federation, 2012, describing a method for preparing boron-containing hyaluronic acid. No funding sources had any role in the design of the study; in the collection, analysis or interpretation of data; in the writing of the manuscript, or in the decision to publish the results. The other authors declare no conflicts of interest.

\section{References}

1. Grimes, R.N. Carboranes in Medicine. In Carboranes, 3rd ed.; Grimes, R.N., Ed.; Academic Press: Cambridge, MA, USA, 2016; pp. 945-984, ISBN 9780128018941.

2. Nakamura, H.; Ueno, M.; Lee, J.-D.; Ban, H.S.; Justus, E.; Fan, P.; Gabel, D. Synthesis of dodecaborateconjugated cholesterols for efficient boron delivery in neutron capture therapy. Tetrahedron Lett. 2007, 48, 3151-3154. [CrossRef]

3. Schaffran, T.; Lissel, F.; Samatanga, B.; Karlsson, G.; Burghardt, A.; Edwards, K.; Winterhalter, M.; Peschka-Süss, R.; Schubert, R.; Gabel, D. Dodecaborate cluster lipids with variable headgroups for boron neutron capture therapy: Synthesis, physical-chemical properties and toxicity. J. Organomet. Chem. 2009, 694, 1708-1712. [CrossRef]

4. Crossley, E.L.; Ziolkowski, E.J.; Coderre, J.A.; Rendina, L.M. Boronated DNA-binding compounds as potential agents for boron neutron capture therapy. Mini Rev. Med. Chem. 2007, 7, 303-313. [CrossRef] [PubMed]

5. Ching, H.Y.; Clarke, R.J.; Rendina, L.M. Supramolecular $\beta$-cyclodextrin adducts of boron-rich DNA metallointercalators containing dicarba-closo-dodecaborane(12). Inorg. Chem. 2013, 52, 10356-10367. [CrossRef] [PubMed] 
6. Yinghuai, Z.; Yan, K.C.; Maguire, J.A.; Hosmane, N.S. Resent developments in boron neutron capture therapy (BNCT) driven by nanotechnology. Curr. Chem. Biol. 2007, 1, 141-149. [CrossRef]

7. Yinghuai, Z.; Maguire, J.A.; Hosmane, N.S. Resent developments in boron neutron capture therapy driven by nanotechnology, Boron for Living: Boron Neutron Capture Therapy. In Boron Science: New Technologies and Applications; Hosmane, N.S., Ed.; CRC Press: Boca Raton, FL, USA, 2011; pp. 147-163, ISBN 9781439826621.

8. Gao, Z.; Horiguchi, Y.; Nakai, K.; Matsumura, A.; Suzuki, M.; Ono, K.; Nagasaki, Y. Use of boron cluster-containing redox nanoparticles with ROS scavenging ability in boron neutron capture therapy to achieve high therapeutic efficiency and low adverse effects. Biomaterials 2016, 104, 201-212. [CrossRef] [PubMed]

9. Laurenţia, G.N.; Rodica, A.M. Boron neutron capture therapy: Delivery agents used in boron administration. Ther. Pharmacol. Clin. Toxicol. 2016, 20, 25-32.

10. Barth, R.F.; Vicente, M.G.; Harling, O.K.; Kiger, W.S., 3rd; Riley, K.J.; Binns, P.J.; Wagner, F.M.; Suzuki, M.; Aihara, T.; Kato, I.; et al. Current status of boron neutron capture therapy of high grade gliomas and recurrent head and neck cancer. Radiat. Oncol. 2012, 7, 146. [CrossRef] [PubMed]

11. Volkov, V.P.; Zelenetskii, A.N.; Ivanov, P.L.; Mikhajlova, N.P.; Molin, A.A.; Seljanin, M.A.; Khabarov, V.N.; Chernyshenko, A.O. Method for preparing boron-containing hyaluronic acid. Russian Federation Patent 2445978, 2012.

12. Haxaire, K.; Maréchal, Y.; Milas, M.; Rinaudo, M. Hydration of hyaluronan polysaccharide observed by IR spectrometry. II: Definition and quantitative analysis of elementary hydration spectra and water uptake. Biopolymers 2003, 72, 149-161. [CrossRef] [PubMed]

13. Maréchal, Y.; Milas, M.; Rinaudo, M. Hydration of hyaluronan polysaccharide observed by IR spectrometry. III: Structure and mechanism of hydration. Biopolymers 2003, 72, 162-173. [CrossRef] [PubMed]

14. Vasi, A.M.; Popa, M.I.; Butnaru, M.; Dodi, G.; Verestiuc, L. Chemical functionalization of hyaluronic acid for drug delivery applications. Mater. Sci. Eng. C 2014, 38, 177-185. [CrossRef] [PubMed]

15. Alkrad, J.A.; Mrestani, Y.; Stroehl, D.; Wartewig, S.; Neubert, R. Characterization of enzymatically digested hyaluronic acid using NMR, Raman, IR, and UV-Vis spectroscopes. J. Pharm. Biomed. Anal. 2003, 31, 545-550. [CrossRef]

16. Duarte, M.L.; Ferreira, M.C.; Marvão, M.R.; Rocha, J. An optimised method to determine the degree of acetylation of chitin and chitosan by FTIR spectroscopy. Int. J. Biol. Macromol. 2002, 31, 1-8. [CrossRef]

17. Van den Berg, R.; Peters, J.A.; van Bekkum, H. The structure and (local) stability constants of borate esters of mono- and di-saccharides as studied by 11B and 13C NMR spectroscopy. Carbohydr. Res. 1994, 253, 1-12. [CrossRef]

18. Sen, S. Temperature induced structural changes and transport mechanisms in borate, borosilicate and boroaluminate liquids: High-resolution and high-temperature NMR results. J. Non-Cryst. Solids 1999, 253, 84-94. [CrossRef]

19. Dubrovskii, S.A.; Zelenetskii, A.N.; Uspenskii, S.A.; Khabarov, V.N. Effect of borax additives on the rheological properties of sodium hyaluronate aqueous solutions. Polym. Sci. Ser. A 2014, 56, 205-210. [CrossRef]

20. Grafstein, D.; Dvorak, J. Neocarboranes, a new family of stable organoboranes isomeric with the carboranes. Inorg. Chem. 1963, 2, 1128-1133. [CrossRef]

21. Snyder, H.R.; Reedy, A.J.; Lennarz, W.J. Synthesis of aromatic boronic acids. Aldehydo boronic acids and a boronic acid analog of tyrosine. J. Am. Chem. Soc. 1958, 80, 835-838. [CrossRef]

22. Soloway, A.H.; Wright, R.L.; Messer, J.R. Evaluation of boron compounds for use in neutron-capture therapy of brain tumors. I. Animal investigations. J. Pharmacol. Exp. Therap. 1961, 134, 117-122.

23. Ichihashi, M.; Nakanishi, T.; Mishima, Y. Specific killing effect of 10B1-para-boronophenylalanine in thermal neutron capture therapy of malignant melanoma: In vitro radiobiological evaluation. J. Investig. Dermatol. 1982, 78, 215-218. [CrossRef] [PubMed]

24. Barth, R.F. A critical assessment of boron neutron capture therapy: An overview. J. Neurooncol. 2003, 62, 1-5. [CrossRef] [PubMed]

25. Steed, J.W.; Atwood, J.L. Supramolecular Chemistry, 2nd ed.; John Wiley \& Sons, Ltd.: Hoboken, NJ, USA, 2009; ISBN 978-0-470-51234-0.

26. Lenz, R.W.; Heeschen, J.P. The application of nuclear magnetic resonance to structural studies of carbohydrates in aqueous solution. J. Polym. Sci. A 1961, 51, 247-261. [CrossRef] 
27. Smith, J.T.; Rassi, Z.E. Micellar electrokinetic capillary chromatography with in situ charged micelles IV. Influence of the nature of the alkylglycoside surfactant. J. Chromatogr. A 1994, 685, 131-143. [CrossRef]

28. Hall, D.G. Boronic Acids. Preparation, Application in Organic Synthesis and Medicine; Wiley-VCH Verlag GmbH \& Co. KGaA: Weinheim, Germany, 2006; ISBN 978-3-527-32598-6.

29. Choi, K.Y.; Saravanakumar, G.; Park, J.H.; Park, K. Hyaluronic acid-based nanocarriers for intracellular targeting: Interfacial interactions with proteins in cancer. Colloids Surf. B Biointerfaces 2012, 99, 82-94. [CrossRef] [PubMed]

30. Toole, B.P. Hyaluronan: From extracellular glue to pericellular cue. Nat. Rev. Cancer 2004, 4, 528-539. [CrossRef] [PubMed]

31. Auvinen, P.; Tammi, R.; Parkkinen, J.; Tammi, M.; Agren, U.; Johansson, R.; Hirvikoski, P.; Eskelinen, M.; Kosma, V.M. Hyaluronan in peritumoral stroma and malignant cells associates with breast cancer spreading and predicts survival. Am. J. Pathol. 2000, 156, 529-536. [CrossRef]

32. Ropponen, K.; Tammi, M.; Parkkinen, J.; Eskelinen, M.; Tammi, R.; Lipponen, P.; Agren, U.; Alhava, E.; Kosma, V.M. Tumor cell-associated hyaluronan as an unfavorable prognostic factor in colorectal cancer. Cancer Res. 1998, 58, 342-347. [PubMed]

33. Setala, L.P.; Tammi, M.I.; Tammi, R.H.; Eskelinen, M.J.; Lipponen, P.K.; Agren, U.M.; Parkkinen, J.; Alhava, E.M.; Kosma, V.M. Hyaluronan expression in gastric cancer cells is associated with local and nodal spread and reduced survival rate. Br. J. Cancer 1999, 79, 1133-1138. [CrossRef] [PubMed]

34. Selyanin, M.A.; Boykov, P.Y.; Khabarov, V.N.; Polyak, F. Hyaluronic Acid: Production, Properties, Application in Biology and Medicine; Translation, Ed.; John Wiley \& Sons, Ltd.: Hoboken, NJ, USA, 2015; ISBN 978-1-118-63379-3.

35. De Maio, M.; Rzany, B. Injectable Fillers in Aesthetic Medicine; Springer: Berlin/Heidelberg, Germany, 2014; ISBN 978-3-642-45125-6.

36. Akopova, T.A.; Zelenetskii, A.N.; Ozerin, A.N. Solid state synthesis and modification of chitosan. In Focus on Chitosan Research; Ferguson, A.N., O'Neill, A.G., Eds.; Nova Science Publishers, Inc.: New York, NY, USA, 2011; pp. 223-254, ISBN 978-1-62081-841-1.

37. Demina, T.S.; Akopova, T.A.; Vladimirov, L.V.; Shchegolikhin, A.N.; Kechek'yan, A.S.; Perov, N.S.; Chernyshenko, A.O.; Zelenetskii, A.N. The study of the interaction between chitosan and 2,2-Bis(hydroxymethyl)propionic acid during solid-phase synthesis. Polym. Sci. Ser. B 2011, 53, 358-370. [CrossRef]

38. Akopova, T.A.; Timashev, P.S.; Demina, T.S.; Bardakova, K.N.; Minaev, N.V.; Burdukovskii, V.F.; Cherkaev, G.V.; Vladimirov, L.V.; Istomin, A.V.; Svidchenko, E.A.; et al. Solid-state synthesis of unsaturated chitosan derivatives to design 3D structures through two-photon-induced polymerization. Mendeleev. Commun. 2015, 25, 280-282. [CrossRef]

39. Schantea, C.E.; Zubera, G.; Herlinb, C.; Vandamme, T.F. Chemical modifications of hyaluronic acid for the synthesis of derivatives for a broad range of biomedical applications. Carbohydr. Polym. 2011, 85, 469-489. [CrossRef]

(C) 2018 by the authors. Licensee MDPI, Basel, Switzerland. This article is an open access article distributed under the terms and conditions of the Creative Commons Attribution (CC BY) license (http:/ / creativecommons.org/licenses/by/4.0/). 